\title{
Performance and stability of mirror coatings for the ATHENA mission
}

Della Monica Ferreira, Desiree; Svendsen, Sara ; Massahi, Sonny; Jafari, Atefeh; Vu, Lan M. ; Korman, Jakob; Gellert, Nis C.; Christensen, Finn E.; Kadkhodazadeh, Shima; Kasama, Takeshi

Total number of authors:

18

Published in:

Proceedings of Spie

Link to article, DOI:

$10.1117 / 12.2313275$

Publication date:

2018

Document Version

Publisher's PDF, also known as Version of record

Link back to DTU Orbit

Citation (APA):

Della Monica Ferreira, D., Svendsen, S., Massahi, S., Jafari, A., Vu, L. M., Korman, J., Gellert, N. C. Christensen, F. E., Kadkhodazadeh, S., Kasama, T., Shortt, B., Bavdaz, M., Collon, M. J., Landgraf, B., Krumrey, M., Cibik, L., Schreiber, S., \& Schubert, A. (2018). Performance and stability of mirror coatings for the ATHENA mission. In Proceedings of Spie [106993K] SPIE - International Society for Optical Engineering. Proceedings of SPIE - The International Society for Optical Engineering https://doi.org/10.1117/12.2313275

\section{General rights}

Copyright and moral rights for the publications made accessible in the public portal are retained by the authors and/or other copyright owners and it is a condition of accessing publications that users recognise and abide by the legal requirements associated with these rights.

- Users may download and print one copy of any publication from the public portal for the purpose of private study or research.

- You may not further distribute the material or use it for any profit-making activity or commercial gain

- You may freely distribute the URL identifying the publication in the public portal 


\section{Performance and stability of mirror coatings for the ATHENA mission}

Desirée Della Monica Ferreira, Sara Svendsen, Sonny Massahi, Atefeh Jafari, Lan M. Vu, et al.

Desirée Della Monica Ferreira, Sara Svendsen, Sonny Massahi, Atefeh Jafari, Lan M. Vu, Jakob Korman, Nis C. Gellert, Finn E. Christensen, Shima Kadkhodazadeh, Takeshi Kasama, Brian Shortt, Marcos Bavdaz, Maximilien J. Collon, Boris Landgraf, Michael Krumrey, Levent Cibik, Swenja Schreiber, Anja Schubert, "Performance and stability of mirror coatings for the ATHENA mission," Proc. SPIE 10699, Space Telescopes and Instrumentation 2018: Ultraviolet to Gamma Ray, 106993K (6 July 2018); doi: 10.1117/12.2313275

Event: SPIE Astronomical Telescopes + Instrumentation, 2018, Austin, Texas, United States 


\title{
Performance and Stability of Mirror Coatings for the ATHENA Mission
}

\author{
Desiree Della Monica Ferreira ${ }^{a}$, Sara Svendsen ${ }^{a}$, Sonny Massahi ${ }^{a}$, Atefeh Jafari ${ }^{a}$, Lan M. Vu $^{a}$, \\ Jakob Korman ${ }^{a}$, Nis C. Gellert ${ }^{a}$, Finn E. Christensen ${ }^{a}$, Shima Kadkhodazadeh ${ }^{b}$, Takeshi \\ Kasama $^{b}$, Brian Shortt ${ }^{c}$, Marcos Bavdaz ${ }^{c}$, Maximilien J. Collon ${ }^{d}$, Boris Landgraf ${ }^{d}$, Michael \\ Krumrey $^{e}$, Levent Cibik $^{e}$, Swenja Schreiber $^{e}$ and Anja Schubert ${ }^{e}$

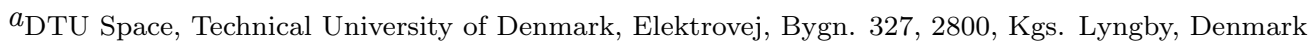

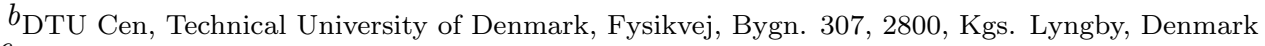 \\ ${ }^{c}$ European Space Agency (ESTEC), Keplerlaan 1, PO Box 299, 2200 AG, Noordwijk, Netherlands \\ $d_{\text {cosine B.V., Oosteinde } 36,2361 \text { HE Warmond, Netherlands }}$

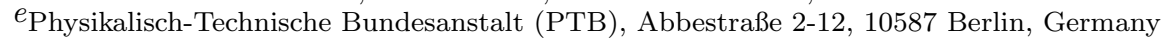

\begin{abstract}
We present the expected coating performance based on design and simulations, tested coating performance evaluated by means of X-ray reflectometry and short and long term stability of several materials considered as coating options for the X-ray mirrors of the ATHENA mission. As part of this study we also report on the compatibility of the X-ray reflecting coatings to the industrial processes involved in the assembly of mirror modules using Silicon Pore Optics technology.
\end{abstract}

Keywords: ATHENA, SPO, coating design, X-ray mirrors, XRR, multilayer, X-ray optics, Ir/B ${ }_{4} \mathrm{C}, \mathrm{Ir} / \mathrm{SiC}, \mathrm{Ir}$, effective area

\section{INTRODUCTION}

ATHENA (Advanced Telescope for High Energy Astrophysics) ${ }^{1}$ is the second Large class mission selected by ESA with planned launch in the early 2030s. ATHENA will operate in the X-ray range between $0.1 \mathrm{keV}$ and 10 $\mathrm{keV}$ to address the Hot and Energetic Universe scientific theme.

As the technology behind the X-ray optics for ATHENA evolves from its original concept, ${ }^{2}$ so does the developments of the mirror coatings for the many Silicon Pore Optics (SPO) X-ray mirrors that will be on-board the observatory. ${ }^{3-9}$ The latest update on the geometry of the optics sets new requirements for the telescope onaxis effective area. Furthermore, instability of the $\mathrm{B}_{4} \mathrm{C}$ coating can challenge the performance of the telescope at $1 \mathrm{keV} .{ }^{10}$

Single metal coatings were used in previous X-ray observatories to achieve a high reflectivity in the energy range $0.1 \mathrm{keV}$ to $10 \mathrm{keV}$. The critical angle for total external reflection is maximized with the goal of achieving maximum overall throughput for the telescope.

The use of a light material, such as $\mathrm{B}_{4} \mathrm{C}$, on top of a metal coating, such as $\mathrm{Ir}$, enhances the throughput at low energies and it is particularly relevant in the energy range between $0.1 \mathrm{keV}$ and $5 \mathrm{keV} \mathrm{keV} \cdot{ }^{3,4}$ The light material coating can be optimized so it does not jeopardize the throughput at higher energies. ${ }^{10}$ In the case of a bilayer made of a heavy, high-z material, with a top layer of a light, low-z material, the reflectance of the low-Z material is higher than of the high- $Z$ material for grazing incident angles smaller than the critical angle because of the smaller extinction coefficient. That also allows for higher energy photons to penetrate the low- $\mathrm{Z}$ material and be reflected by the high-Z material without significant loss. To improve throughput in the low energy range between $0.1 \mathrm{keV}$ and $5.0 \mathrm{keV}$ and at the same time enhance performance beyond $5 \mathrm{keV}$, the use a linear graded multilayer underneath an optimized heavy/light bilayer is a suitable alternative. ${ }^{10}$

Further author information:

Send correspondence to:

Desiree Della Monica Ferreira, e-mail: desiree@space.dtu.dk

Space Telescopes and Instrumentation 2018: Ultraviolet to Gamma Ray, edited by Jan-Willem A. den Herder, Shouleh Nikzad, Kazuhiro Nakazawa, Proc. of SPIE Vol. 10699, 106993K · @ 2018 SPIE CCC code: $0277-786 X / 18 / \$ 18 \cdot$ doi: $10.1117 / 12.2313275$ 


\begin{tabular}{cccc}
\hline \hline Ring & Width $(\mathrm{mm})$ & Length $(\mathrm{mm})$ & Mid Radius $(\mathrm{m})$ \\
\hline 1 & 37.096 & 101.504 & 0.286 \\
2 & 50.158 & 83.388 & 0.348 \\
3 & 49.838 & 70.762 & 0.411 \\
4 & 49.613 & 61.460 & 0.473 \\
5 & 89.363 & 54.321 & 0.535 \\
6 & 82.476 & 48.671 & 0.597 \\
7 & 77.571 & 44.087 & 0.659 \\
8 & 86.892 & 40.294 & 0.722 \\
9 & 82.053 & 37.104 & 0.784 \\
10 & 90.205 & 34.383 & 0.846 \\
11 & 85.538 & 32.036 & 0.908 \\
12 & 92.782 & 29.990 & 0.970 \\
13 & 88.326 & 28.191 & 1.032 \\
14 & 94.845 & 26.597 & 1.095 \\
15 & 90.608 & 25.175 & 1.157 \\
\hline \hline
\end{tabular}

Table 1. Geometry of the X-ray mirrors for each SPO mirror module ring. ${ }^{12}$

Optimization of the coating design along with investigation of the performance and stability of the possible materials presenting performance close to that expected for $\mathrm{B}_{4} \mathrm{C}$ can improve the throughput at lower energies and allow for the requirements on the effective area to be met.

The newest concept adopted for the ATHENA optics considered for the results presented her is of a fixed focal length of $12 \mathrm{~m}$ single telescope consisting of 15 rings of SPO mirror modules, each module is made of two sets of 68 reflecting X-ray mirrors. The entire optics containing 678 mirror modules. Because of the reduction in the geometry of the optics from 20 mirror module rings to 15 mirrors module rings, the new requirement for ATHENA's on-axis effective area is $1.4 \mathrm{~m}^{2}$ at $1 \mathrm{keV}$ and $0.25 \mathrm{~m}^{2}$ at $6 \mathrm{keV}$.

In this study we present both expected coating performance based on theoretical models and experimental results on $\mathrm{Ir}, \mathrm{B}_{4} \mathrm{C}$ and $\mathrm{SiC}$ coatings.

\section{COATING DESIGN AND EXPECTED PERFORMANCE}

The effective area of the telescope depends on the collecting area of the optics and the capacity of mirrors in reflecting X-rays. The low energy photons will be successfully reflected throughout the optics while the higher energy photons are mostly reflected in the inner rings of mirror modules. ${ }^{10}$ By removing the outermost five mirror module rings, the effect will be larger at energies below $4 \mathrm{keV}$ without affecting the telescope performance beyond $5 \mathrm{keV}$.

In this study we compute the on-axis effective area based on the updated geometry of the ATHENA optics and consider the performance of different materials. The computation makes use of the most recent coating optimization designs ${ }^{10}$ obtained by evaluating the coating performance over the integrated energy range of ATHENA. The on-axis effective areas computed are illustrated in figure 1. The configuration of the SPO mirror modules considered is listed in table 1. The coating models considered for computation of effective areas were generated using the IMD software. ${ }^{11}$ The same coating recipe is considered for all mirror modules with an average surface roughness of $0.45 \mathrm{~nm}$.

The computed on-axis effective at $1 \mathrm{keV}$ and $6 \mathrm{keV}$ based on the expected performance of the coating designs is listed in table 2. As expected, the reduction of the five outermost mirror module rings affects the telescope performance significantly at $1 \mathrm{keV}$. Based on the theoretical models considered here, the $\mathrm{Ir} / \mathrm{B}_{4} \mathrm{C}$ bilayer coating can still provide an effective area above the required at $1 \mathrm{keV}$. At $6 \mathrm{keV}$ the performance is just below the requirement. As reported previously, the use of multilayer coatings can improve the performance at $6 \mathrm{keV} .{ }^{10}$

In terms of performance, the $\mathrm{Ir} / \mathrm{B}_{4} \mathrm{C}$ bilayer coating is closely followed by the $\mathrm{Ir} / \mathrm{SiC}$ bilayer, motivating the consideration of $\mathrm{SiC}$ as replacement for $\mathrm{B}_{4} \mathrm{C}$. The recipe considered for $\mathrm{Ir} / \mathrm{SiC}$ is $10 \mathrm{~nm}$ of $\mathrm{Ir}$ with a top layer of 


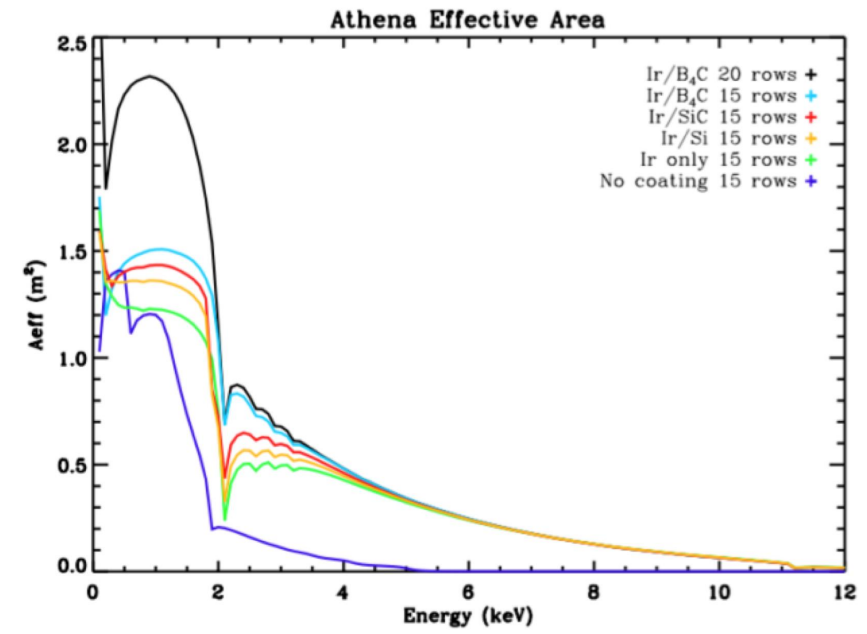

Figure 1. On-axis effective area curves of the ATHENA telescope considering the previous 20 mirror module rings geometry compared to the 15 mirror module rings geometry and coating designs for different materials.

\begin{tabular}{cccc}
\hline \hline Coating & Geometry & Aeff $1 \mathrm{keV}\left(\mathrm{m}^{2}\right)$ & Aeff $6 \mathrm{keV}\left(\mathrm{m}^{2}\right)$ \\
\hline $\mathrm{Ir} / \mathrm{B}_{4} \mathrm{C}$ bilayer & 20 rings & 2.3093 & 0.2469 \\
$\mathrm{Ir} / \mathrm{B}_{4} \mathrm{C}$ bilayer & 15 rings & 1.5067 & 0.2468 \\
$\mathrm{Ir} / \mathrm{SiC}$ bilayer & 15 rings & 1.4344 & 0.2424 \\
$\mathrm{Ir} / \mathrm{Si}$ bilayer & 15 rings & 1.3612 & 0.2428 \\
$\mathrm{Ir}$ single layer & 15 rings & 1.2271 & 0.2394 \\
no coating & 15 rings & 1.2008 & 0.0003 \\
\hline \hline
\end{tabular}

Table 2. On-axis effective area (Aeff) at $1 \mathrm{keV}$ and $6 \mathrm{keV}$ of the ATHENA telescope considering the previous 20 mirror module rings geometry compared to the 15 mirror module rings geometry and coating designs for different materials.

$\mathrm{SiC}$ of $4 \mathrm{~nm}$. Experimental considerations on stability of both $\mathrm{Ir} / \mathrm{B}_{4} \mathrm{C}$ and $\mathrm{Ir} / \mathrm{SiC}$ bilayers are presented in this study.

\section{STABILITY OF IRIDIUM AND BORON CARBIDE COATINGS}

\subsection{Short and long term stability}

The first coated SPO samples representative of the present ATHENA optics were produced back in 2011 at DTU Space. Since then, coating characterization by using X-ray reflectometry (XRR) has been performed by DTU Space both using the $\mathrm{Cu} \mathrm{K} \mathrm{K}_{\alpha} 8 \mathrm{keV}$ source at the X-ray facility at DTU Space and with synchrotron radiation at the four-crystal monochromator (FCM) beamline in the laboratory of PTB at BESSY II in Berlin. ${ }^{13}$ This beamline provides monochromatic radiation of high spectral purity in the photon energy range from $1.75 \mathrm{keV}$ to $10 \mathrm{keV}$. It is equipped with a UHV-reflectometer providing all 6 degrees of freedom for sample positioning. ${ }^{14}$ The samples are loaded via a vacuum load-lock system. During the last years, the set-up has been further improved. Now, typically 8 witness samples or up to 4 SPO samples can be loaded. After finding the alignment settings for each sample, the alignment is verified using at CCD-camera system at about $1.5 \mathrm{~m}$ from the sample. One pixel on the CCD corresponds to a change of the grazing incidence angle of about 2 arcsec. All angle scans at fixed photon energy or energy scans at fixed angle are started simultaneously so that the real measurements can run automatically over night. A further improvement is an additional slit system directly in front of the samples and a thin photodiode after this beam defining slit which is used for normalization of the incoming beam. With this transmission photodiode in the beam, the photon energy range from $3 \mathrm{keV}$ to $10 \mathrm{keV}$ is accessible. The results of these measurements have been analyzed individually, ${ }^{5-7,10}$ for a few selected samples recurrent measurements were performed between 2012 and 2017 allowing for an evaluation of the stability of the $\mathrm{Ir} / \mathrm{B}_{4} \mathrm{C}$ coatings, until recently considered as baseline for the ATHENA mission. 
In this study we present the measurements of two SPO samples, one coated with a $\mathrm{Ir} / \mathrm{B}_{4} \mathrm{C}$ bilayer with a $\mathrm{Cr}$ undercoat layer to balance stress and another with a $\mathrm{Ir} / \mathrm{B}_{4} \mathrm{C}$ linear graded multilayer. Both recipes considered are optimized coating designs considered to enhance the performance of the ATHENA X-ray mirrors. ${ }^{4}$

The sample SPO 05-03-07 is coated with a $\mathrm{Cr} / \mathrm{Ir} / \mathrm{B}_{4} \mathrm{C}$ trilayer. Energy scans in the range between $3 \mathrm{keV}$ and $10 \mathrm{keV}$ of the sample have been performed at the laboratory of PTB at BESSY II in 2012, 2013, 2014 and 2017 at $0.6^{\circ}$ grazing incidence angle.

The data measured at the different times are presented in figure 2. From the plot it is clear that the reflective performance of the coating has changed significantly between the measurements taken just after coating in 2012 and after one year in 2013. However, from the data obtained in 2014 and 2017, the coating appears to have stabilized since the initial change.

The theoretical models for each coating were fit to the XRR data using the IMD software. ${ }^{11}$ Models fitted to energy scans from 2012 and 2013 are presented with the respective data sets in figure 3 . The drastic change in the shape of the reflectivity curve over time can be attributed to oxidation and/or reduced density of the material in the top layer. Thus, instead of $\mathrm{B}_{4} \mathrm{C}$ the model fitted to the data has a $\mathrm{B}_{2} \mathrm{O}_{3}$ top layer whose density has been used as a fit parameter. The use of $\mathrm{B}_{2} \mathrm{O}_{3}$ is motivated by a independent study of $\mathrm{B}_{4} \mathrm{C}$ chemical stability performed at DTU Space. ${ }^{15}$ The densities of Ir and Cr were kept fixed at their nominal value.

The resulting best-fit model was able to give a reasonable fit to the data at the lower energies, although the fitted thickness of the top layer material is larger in comparison to the previous $\mathrm{Cr} / \mathrm{Ir} / \mathrm{B}_{4} \mathrm{C}$ model based on 2012 data. Further studies on the oxidization of the $\mathrm{B}_{4} \mathrm{C}$ are being carried out. The best-fit parameters obtained are listed in table 3.
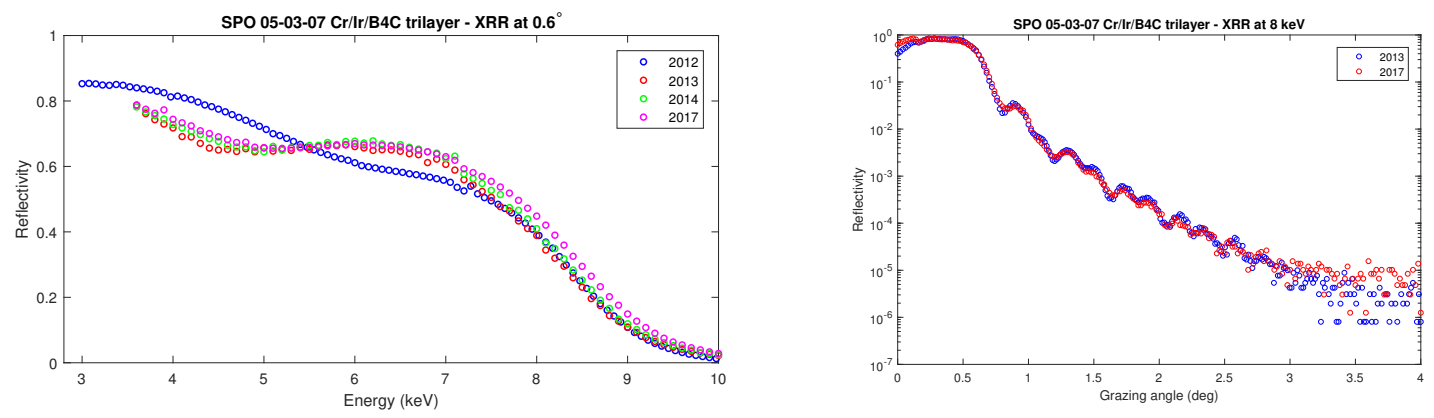

Figure 2. Energy scan at $0.6^{\circ}$ (left) beasured at the laboratory of PTB at BESSY II and angle scan at $8 \mathrm{keV}$ (right) measured at DTU Space of SPO 05-03-07 coated with a Cr/Ir/B 4 C trilayer measured between 2012 and 2017.

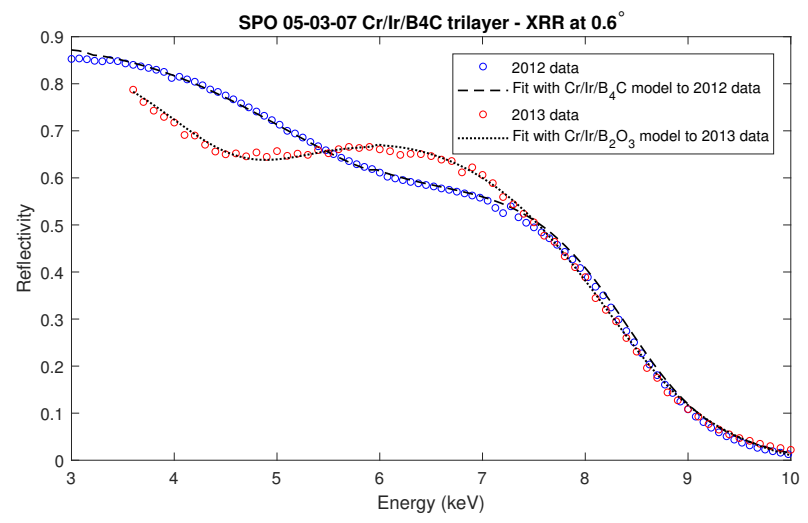

Figure 3. Energy scan measurements at $0.6^{\circ}$ of SPO $05-03-07$ coated with a $\mathrm{Cr} / \mathrm{Ir} / \mathrm{B}_{4} \mathrm{C}$ trilayer along with the best-fit theoretical IMD models. 


\begin{tabular}{cccccccc}
\hline \hline Scan & Year & Model & $z_{\mathrm{Cr}}(\mathrm{nn})$ & $z_{\mathrm{Ir}}(\mathrm{nm})$ & $z_{\text {top }}(\mathrm{nm})$ & $\rho_{\text {top }}\left(\mathrm{g} / \mathrm{cm}^{3}\right)$ & $\langle\sigma\rangle(\mathrm{nm})$ \\
\hline $\mathrm{E}\left(0.6^{\circ}\right)$ & 2012 & $\mathrm{Cr} / \mathrm{Ir} / \mathrm{B}_{4} \mathrm{C}$ & 11.78 & 8.07 & 8.67 & 2.52 & 0.94 \\
$\mathrm{E}\left(0.6^{\circ}\right)$ & 2013 & $\mathrm{Cr} / \mathrm{Ir} / \mathrm{B}_{2} \mathrm{O}_{3}$ & 11.67 & 8.9 & 12.32 & 2.02 & 0.71 \\
\hline \hline
\end{tabular}

Table 3. Best-fit results of energy scan measurements of SPO 05-03-07 Cr/ $\mathrm{Ir} / \mathrm{B}_{4} \mathrm{C}$ trilayer.

The second sample considered is SPO 123-03-30, an Ir/ $\mathrm{B}_{4} \mathrm{C}$ linear graded multilayer coated SPO sample consisting of five linear graded bilayers with an optimized $\mathrm{Ir} / \mathrm{B}_{4} \mathrm{C}$ on top of the graded bilayer. XRR measurements of both energy scans at incident grazing angles of $0.6^{\circ}$ in the energy range $3 \mathrm{keV}$ to $10 \mathrm{keV}$ performed at the FCM beamline of PTB at BESSY II and $8 \mathrm{keV}$ angle scans were performed at DTU Space in 2014 shortly after coating and again in 2017. The measurements are presented in figure 4.

Comparing the energy scan curves, it is possible to observe a decrease in reflectivity at the lower energies. This effect is consistent to partial or total removal of the top $\mathrm{B}_{4} \mathrm{C}$ layer. The change observed at higher energies indicates change in the multilayer structure. The change in performance observed at the energy scan is not observed at the angle scan at $8 \mathrm{keV}$. The best-fit parameters obtained using IMD models are listed in table 4 .
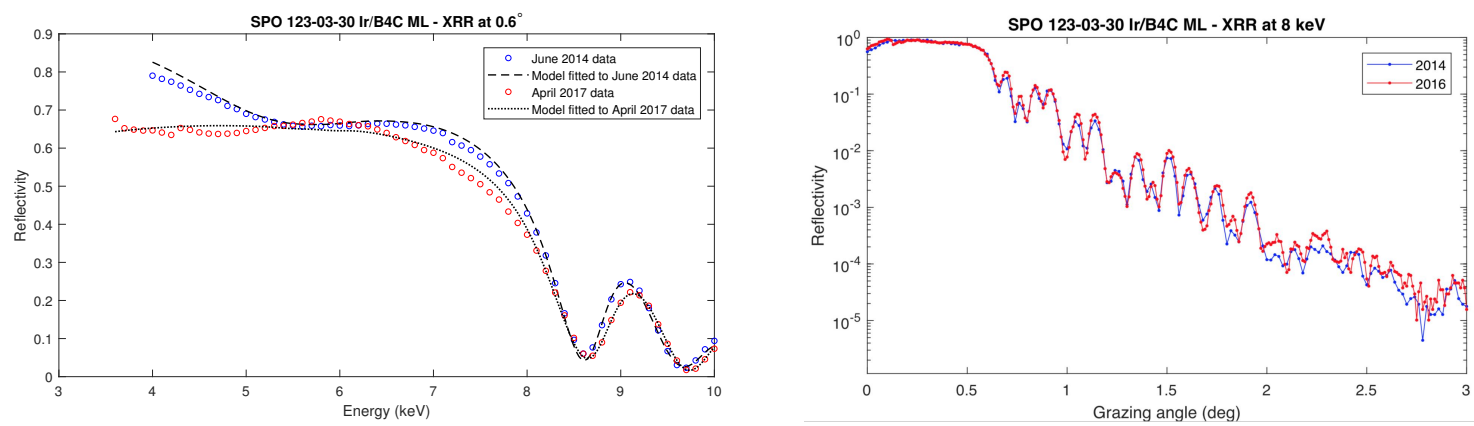

Figure 4. Energy scan measurements at grazing angle of $0.6^{\circ}$ measured in 2014 and 2017 at the FCM beamline of PTB at BESSY II (left) and $8 \mathrm{keV}$ angle scans performed at DTU Space (right) of SPO 123-03-30 coated with $\mathrm{Ir} / \mathrm{B}_{4} \mathrm{C}$ linear graded multilayer coating along with their best-fit IMD models.

\begin{tabular}{c|ccc|ccc}
\hline \hline & \multicolumn{3}{|c|}{ June $2014, \mathrm{E}\left(0.6^{\circ}\right)$} & \multicolumn{3}{c}{ April $2017, \mathrm{E}\left(0.6^{\circ}\right)$} \\
\hline Layer & $z(\mathrm{~nm})$ & $\Gamma$ & $\langle\sigma\rangle(\mathrm{nm})$ & $z(\mathrm{~nm})$ & $\Gamma$ & $\langle\sigma\rangle(\mathrm{nm})$ \\
\hline Top & 9.9 & - & 0.45 & 0.01 & - & 0.45 \\
Cap & 11.4 & - & 1.0 & 10.7 & - & 1.3 \\
$d_{5}$ & 11.0 & 0.32 & 0.61 & 11.5 & 0.32 & 0.63 \\
$d_{4}$ & 9.6 & 0.30 & 0.59 & 9.7 & 0.25 & 0.39 \\
$d_{3}$ & 8.2 & 0.29 & 0.57 & 7.5 & 0.24 & 0.77 \\
$d_{2}$ & 6.8 & 0.26 & 0.63 & 6.5 & 0.32 & 0.63 \\
$d_{1}$ & 5.4 & 0.22 & 0.45 & 5.7 & 0.29 & 0.45 \\
\hline \hline
\end{tabular}

Table 4. Best-fit results of XRR measurements of SPO 123-03-30 coated with an $\mathrm{Ir} / \mathrm{B}_{4} \mathrm{C}$ linear graded multilayer.

\subsection{Imaging multilayers with TEM}

In order to image the individual layers in the coated multilayer and evaluate their composition, we make use of Scanning Transmission Electron Microscopy (STEM) and Electron Energy Loss Spectroscopy (EELS) measurements.

The SPO sample 64-01-25 coated with an Ir/B $\mathrm{B}_{4} \mathrm{C}$ multilayer in 2014 was prepared for STEM via the focused ion beam (FIB) technique using the Helios dual-beam SEM and FIB instrument at DTU CEN. This technique is a reliable and rapid way, with full visual control of the etching procedure. ${ }^{16,17}$ In addition, most of the procedure is performed under high vacuum. 
The sample preparation is a crucial step and affects the quality of STEM results. Herein, we explain briefly how the sample is prepared using FIB. Detailed information on the FIB method and procedures is presented elsewhere. ${ }^{18-20}$

STEM and EELS measurement were performed with the FEI Titan instrument operated in high-angle annular dark field (HAADF) mode at an acceleration voltage of $120 \mathrm{kV}$ with probe size of $\sim 0.7 \mathrm{~nm}$.
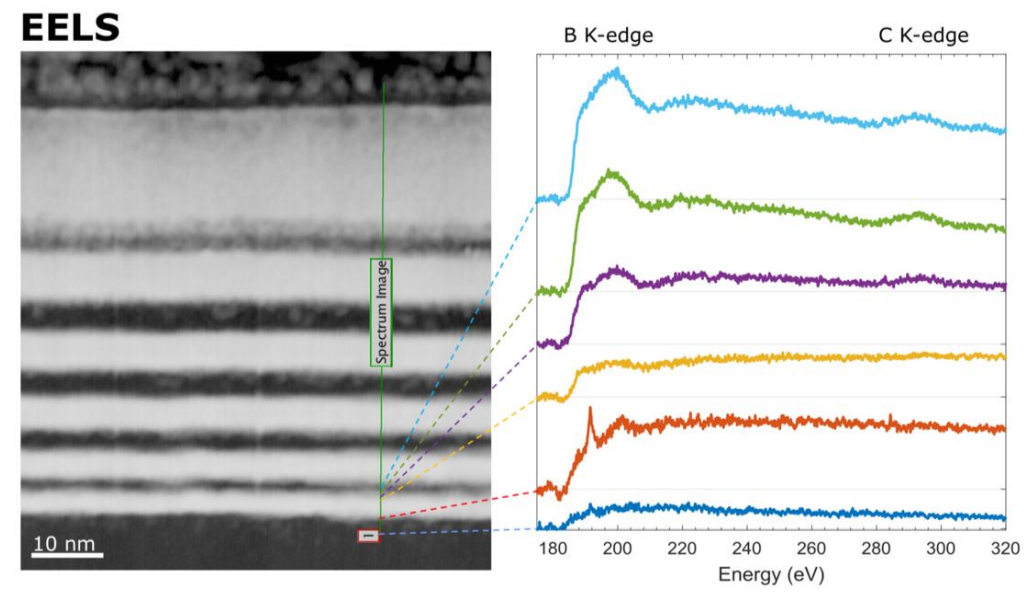

Figure 5. HAADF-STEM image (left) of the $\mathrm{Ir} / \mathrm{B}_{4} \mathrm{C}$ ML sample. The Ir and $\mathrm{B}_{4} \mathrm{C}$ rich layers are light-gray and dark-gray bands in the image, respectively. EELS spectrum (right) revealing the $\mathrm{K}$ edges of boron and carbon.

Figure 5 shows a STEM image of the cross-section of the $\mathrm{Ir} / \mathrm{B}_{4} \mathrm{C}$ multilayer along with an example of the EELS results for B and C analysis. The image reveals 11 distinct layers between the substrate and the very top protective Pt layer, deposited under sample preparation. The contrast between layers in the STEM image arises from differences in the atomic number of heavy Ir and light elements $\mathrm{B}$ and $\mathrm{C}$. The original coating design is made of five linear graded bilayers of $\operatorname{Ir} / \mathrm{B}_{4} \mathrm{C}$ followed by a bilayer of $\operatorname{Ir} / \mathrm{B}_{4} \mathrm{C}$. The six bright layers observed are Ir rich, the 5 darker layers are $\mathrm{B}$ and $\mathrm{C}$ rich layers based on the preliminary EELS analysis, which is consistent with the expected $\mathrm{B}_{4} \mathrm{C}$ layer. The very top layer of $\mathrm{B}_{4} \mathrm{C}$ is not visible in the STEM image and we believe it is removed during the sample preparation. A major disadvantage of the FIB method is working with the heavy Ga ions which cause damages on the surface of materials, ${ }^{16}$ especially for samples with top layer composed of light elements. Although a protective pt layer was used, it is not impossible to consider the destructive nature of the Ga ion beam as a potential culprit.

Considering the instability of the $\mathrm{B}_{4} \mathrm{C}$ layer observed and the technique involved in the sample preparation, it is not possible to evaluate the very top layer of $\mathrm{B}_{4} \mathrm{C}$ with this study. With the exception of the very top layers, the $\mathrm{Ir}$ and $\mathrm{B}_{4} \mathrm{C}$ rich layers are consistent with the desired coating design. A combined study comparing results from XRR, STEM, EELS and X-ray photoelectron spectroscopy (XPS) is ongoing at DTU Space and will soon be reported.

\subsection{Thermal stability}

The SPO mirror modules are stacked upon each other and bonded together with Van-der-Waals bonds, generating rigid and self-supporting mirror modules, without adhesives being needed. ${ }^{21}$ The Van-der-Waals bonds can be turned into even stronger covalent bonds by means of thermal annealing. ${ }^{22}$ Whether or not annealing is required, and what the exact recipe will be, is part of current investigations carried out by ESA and cosine BV. As part of this study, we evaluate the effects of annealing on the coating types under study for ATHENA.

To validate the compatibility of the mirror coatings to the annealing procedure, silicon witness samples (WS) were coated and submitted to the present annealing procedure performed by cosine BV to enhance bonding. The annealing procedure was performed at DTU Space mimicking the same conditions at cosine BV and consists of heating the substrates to a temperature of $200{ }^{\circ} \mathrm{C}$ for 50 hours, added to two hours of pre-heating. 


\begin{tabular}{cccccc}
\hline \hline Samples & Coating & Annealing & $\mathrm{Ir}(\mathrm{nm})$ & $\mathrm{B}_{4} \mathrm{C}(\mathrm{nm})$ & $\mathrm{B}_{2} 0_{3}(\mathrm{~nm})$ \\
\hline si6381 & $\mathrm{Ir} / \mathrm{B}_{4} \mathrm{C}$ & - & 9.2 & 2.4 & 8.2 \\
si6375 & $\mathrm{Ir} / \mathrm{B}_{4} \mathrm{C}$ & $200{ }^{\circ} \mathrm{C}$ & 9.2 & 2.6 & 4.2 \\
si6518 & $\mathrm{Ir}$ & - & 9.2 & - & - \\
si6523 & $\mathrm{Ir}$ & $200{ }^{\circ} \mathrm{C}$ & 9.2 & - & - \\
\hline \hline
\end{tabular}

Table 5. The best-fit values for layer thickness obtained by fitting the theoretical models for each coating the XRR data using the IMD software. ${ }^{11}$

The coating deposition was performed using the DC magnetron sputtering facility at DTU Space and characterization performed by means of XRR. The measurements were performed at the $8 \mathrm{keV}$ X-ray facility at DTU Space and at the FCM beamline of PTB at BESSY II in Berlin. ${ }^{13}$
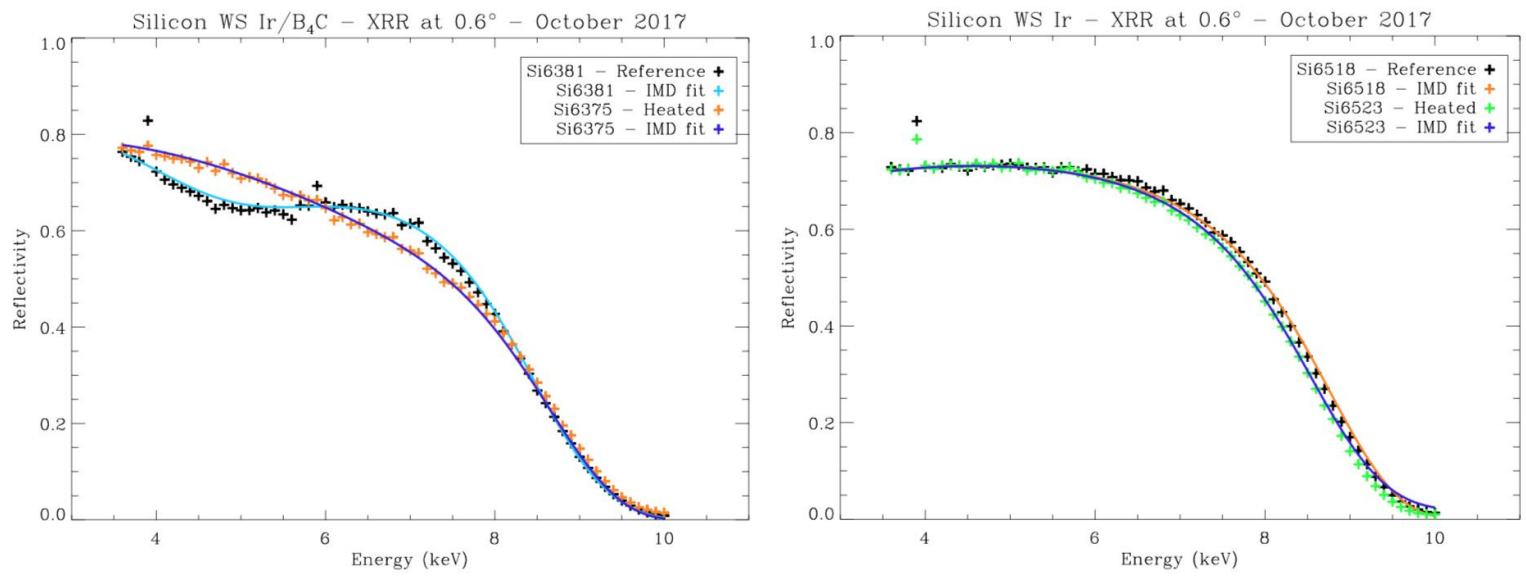

Figure 6. Energy scan measurements for reference and heated $\mathrm{Ir} / \mathrm{B}_{4} \mathrm{C}$ and $\mathrm{Ir}$ only samples

The preliminary results on $\mathrm{Ir} / \mathrm{B}_{4} \mathrm{C}$ bilayer coatings were previously presented, ${ }^{10}$ here we revisit the data and add the results obtained for a single layer of Ir after annealing. The XRR results for both $\mathrm{Ir} / \mathrm{B}_{4} \mathrm{C}$ and $\mathrm{Ir}$ alone are shown in figure 6 . The theoretical models for each coating were fit to the XRR data using the IMD software. ${ }^{11}$ The best-fit results for the layers thicknesses are reported in table 5 .

Motivated by other studies on properties of $\mathrm{B}_{4} \mathrm{C}$ ongoing at DTU Space, ${ }^{15}$ the $\mathrm{B}_{2} \mathrm{O}_{3}$ layer was added to the coating model to account for oxidization of the $\mathrm{B}_{4} \mathrm{C}$ layer. The addition of the oxide layer appears to represent well the data.

The difference in performance of the $\mathrm{Ir} / \mathrm{B}_{4} \mathrm{C}$ coating after the annealing procedure is clear. The shape of the reflectively curve changes dramatically after annealing. There is also a significant variation in the best-fit parameter for layer thickness for the $\mathrm{B}_{2} \mathrm{O}_{3}$, which seems to be vanishing. The best-fit roughness of the $\mathrm{B}_{4} \mathrm{C}$ layer for sample si6375 is $1.6 \mathrm{~nm}$, that is an increase of $1.3 \mathrm{~nm}$ compared to the obtained for the reference, unheated sample, si6381. The best fit roughness for the substrate and Ir interfaces remained as the unheated samples.

For the Ir single layer, the performance of the coating after annealing remains the same, we observed a small degradation of the reflectivity curve due to an increase in the substrate roughness but no change in the Ir layer thickness. The increase in roughness is caused by hydrocarbon contamination of the witness sample and not by changing of the properties of the Ir coating.

The study of thermal stability of coating will be extended to SPO substrates, representative of the ATHENA optics. 


\begin{tabular}{cccc}
\hline \hline Sample ID & Type & Coating & Coating date \\
\hline $217-08$ & SPO & Ir single layer & Feb $/ 2018$ \\
$312-02$ & SPO & Ir/SiC bilayer & Feb $/ 2018$ \\
\hline \hline
\end{tabular}

Table 6. List of silicon pore optics (SPO) samples considered for Ir and $\mathrm{Ir} / \mathrm{SiC}$ coating characterization.

\section{IRIDIUM AND SILICON CARBIDE COATINGS}

Considering the challenges the $\mathrm{B}_{4} \mathrm{C}$ coatings have been presenting, in order to achieve the ambition for the telescope effective area at $1 \mathrm{keV}$, the $\mathrm{Ir} / \mathrm{SiC}$ bilayer design has been proposed where the $\mathrm{SiC}$ top layer substitutes $\mathrm{B}_{4} \mathrm{C}$ to improve the reflectivity in the low energy range. Ir single layer coatings are investigated as well and are considered as an essential reference coating. Assuring that a single simple layer of Ir is compatible with the SPO technology adopted by the ATHENA mission is crucial for further coating development.

The purpose of this study is to determine the stability over time of $\mathrm{Ir}$ and $\mathrm{Ir} / \mathrm{SiC}$ coated samples stored at atmospheric conditions to provide the first results on the suitability of these coatings for the ATHENA mission.

\subsection{Sample preparation and characterization}

The samples considered for Ir and $\mathrm{Ir} / \mathrm{SiC}$ are listed in table 6. Both the SPO samples and witness samples were coated at the DC magnetron sputtering facility at DTU Space according to the optimized coating design. The aimed coating thickness for Ir single-layer samples was $z_{\text {Ir }}=10.0 \mathrm{~nm}$ while the $\mathrm{Ir} / \mathrm{SiC}$ bilayers were optimized to $z_{\text {Ir }}=10.0 \mathrm{~nm}$ with a top layer of $z_{\mathrm{SiC}}=4.0 \mathrm{~nm}$.

The measurements were performed at the $8 \mathrm{keV}$ X-ray facility at DTU Space and at the FCM beamline of PTB at BESSY II. Measurements of the coatings at the laboratory of PTB were performed in March 2018 and May 2018 and include angle scans measured at a fixed energy of $8 \mathrm{keV}$, and energy scans between $3.4 \mathrm{keV}$ and $10.0 \mathrm{keV}$ at fixed grazing incidence angles of $0.6^{\circ}$ and $1.5^{\circ}$. The data was taken on three different positions on each sample (center $\pm 1 \mathrm{~cm}$ ). The energy ranges and the angles of incidence were selected to be representative of the ATHENA telescope.

\subsection{Ir single-layer coatings}

XRR measurements of Ir single-layer coatings are shown in figure 7 which compares BESSY measurements from March 2018 and May 2018 for three positions on SPO 217-08. We detect no significant evolution over time in the energy scan at grazing incident angle of $0.6^{\circ}$ in figure $7 \mathrm{a}$. The same result is observed for the angle scans at $8 \mathrm{keV}$, shown in figure 7 .
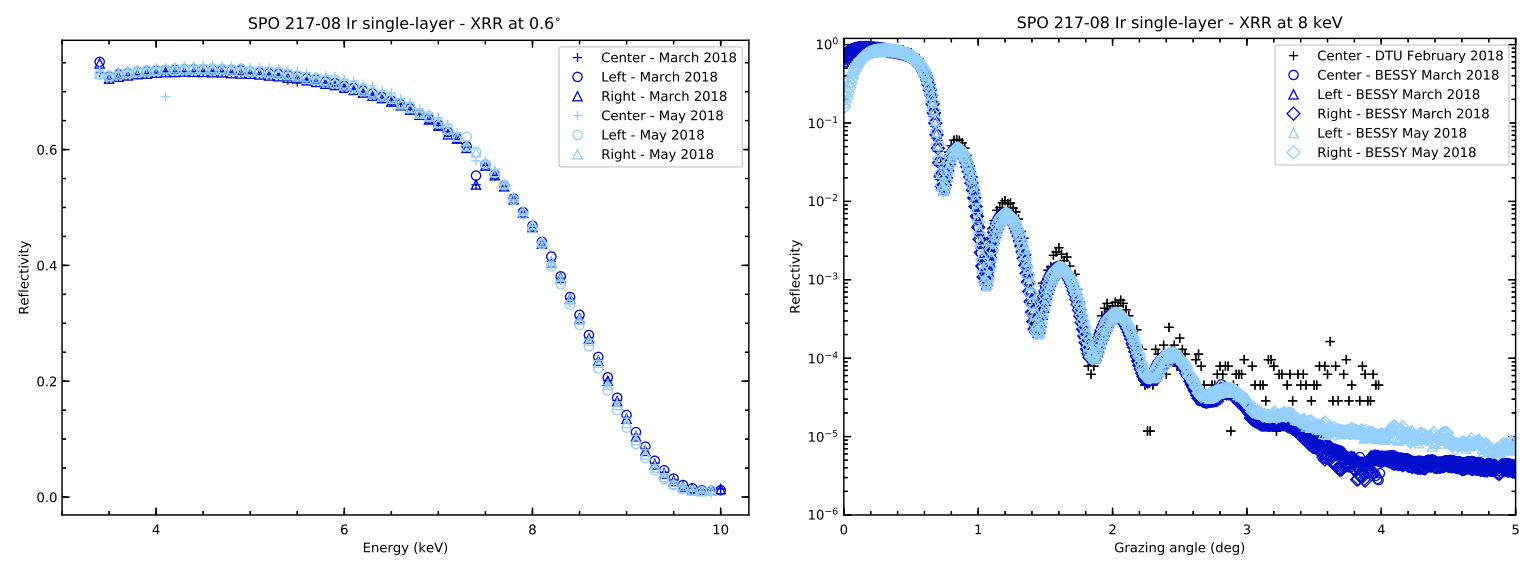

Figure 7. XRR of Ir coated SPO 217-08. The $8 \mathrm{keV}$ angle scan at DTU was measured just after coating, while BESSY measurements were performed 1 month and 3 months after coating. 


\section{3 $\mathrm{Ir} / \mathrm{SiC}$ bilayer coatings}

XRR measurements of $\mathrm{Ir} / \mathrm{SiC}$ bilayer coatings are shown in figure 8 . Figure 8 shows a comparison between BESSY energy scans for three separate positions on Ir/SiC coated samples measured in March and May 2018. The reflectivity in the energy range between $3.4 \mathrm{keV}$ and $7.0 \mathrm{keV}$ which is particularly sensitive to the thickness and composition of the top layer appears unchanged, and hence indicates stability of the SiC film within the two months between measurements. The angle scans presented in figure 8 shows no change from date of coating to measurements taken one month and three months after coating.
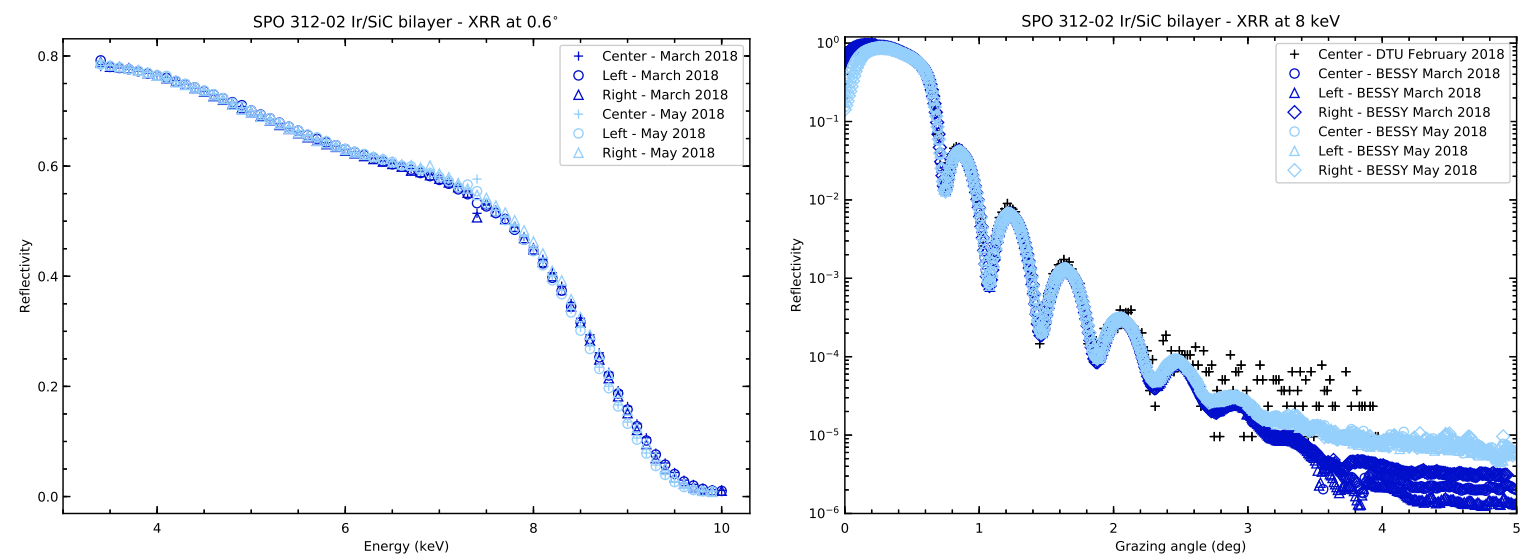

Figure 8. XRR of Ir/SiC coated SPO 312-02. The DTU Space $8 \mathrm{keV}$ angle scan was measured immediately after coating, while BESSY measurements were performed after 1 and 3 months.

\section{SUMMARY}

We present calculations of the telescope effective area for different optics geometries and coating materials. According to the coating expected performance, the $\mathrm{B}_{4} \mathrm{C}$ top layer provides the highest effective area at $1 \mathrm{keV}$ followed by SiC.

The experimental results on coating development show instability of the $\mathrm{B}_{4} \mathrm{C}$ top layer over time where oxidization appears to heavily affect the coating performance. The degradation of the top $\mathrm{B}_{4} \mathrm{C}$ layer is observed on both simple tri-layer and multilayer coatings. Thermal stability studies presented here have also shown that the $\mathrm{Ir} / \mathrm{B}_{4} \mathrm{C}$ bilayer coating is not stable over the annealing at $200{ }^{\circ} \mathrm{C}$. Ir single layer coatings have also been exposed to the annealing procedure. No change in coating performance of Ir was observed and we regard Ir single layer as robust over long time annealing. STEM and EELS techniques are being used to investigate the coating structure and composition and will allow for new insight on the coating stability.

Motivated by the expected performance of coating designs, we further investigate $\mathrm{Ir} / \mathrm{SiC}$ bilayer and $\mathrm{Ir}$ single layer coatings experimental performance. The designed coatings were deposited on SPO substrates representative of the ATHENA optics and characterized with X-ray reflectometry. Both Ir single layer and Ir/SiC bilayer showed no degradation in performance over the period of measurements. The results presented here indicate that $\mathrm{SiC}$ is a suitable alternative to $\mathrm{B}_{4} \mathrm{C}$ and seems to be stable over time. The optimized $\mathrm{Ir} / \mathrm{SiC}$ bilayer coating design consists of $10 \mathrm{~nm}$ Ir with $4 \mathrm{~nm}$ SiC.

The coating development and characterization is an ongoing activity at DTU Space and part of the efforts for achieving the requirements for performance of the ATHENA optics prior to the Mission Adoption Review expected in 2021. The ongoing activities to be reported soon include understanding of coating composition and stability by a combined study comparing results from XRR, STEM, EELS and XPS, evaluation of thermal stability of $\mathrm{Ir} / \mathrm{SiC}$ bilayer coatings, robustness of coatings to the industrial processes involving the production of SPO mirror modules including stability over photolitography and stacking procedures, and systematic characterization of dedicates samples for assessment of short and long term stability of the mirror coatings considered for the ATHENA mission. 


\section{ACKNOWLEDGMENTS}

This activity is funded by the European Space Agency under contract 4000102248/12/NL/PM. The authors acknowledge Zoltan Imre Balogh for his help with FIB sample preparation.

\section{REFERENCES}

[1] Nandra, K., Barret, D., Barcons, X., and et al., "The hot and energetic universe: A white paper presenting the science theme motivating the athena+ mission," astro-ph.HE arXiv:1306.2307 (2013).

[2] Willingale, R., Pareschi, G., Christensen, F., and den Herder, J., "The hot and energetic universe: The optical design of the athena+ mirror," astro-ph.IM arXiv:1307.1709 (2013).

[3] Jakobsen, A. C., Ferreira, D. D. M., Christensen, F. E., Shortt, B., Collon, M., and Ackermann, M. D., "Preliminary coating design and coating developments for ATHENA," Proceedings of SPIE 8147 (2011).

[4] Ferreira, D. D. M., Christensen, F. E., Jakobsen, A. C., Westergaard, N. J. S., and Shortt, B., "ATHENA coating optimization," Proceedings of SPIE 8443 (2012).

[5] Ferreira, D. D. M., Jakobsen, A. C., Christensen, F. E., and et al., "Development and characterization of coatings on Silicon Pore Optics substrates for the ATHENA mission," Proceedings of SPIE 8443 (2012).

[6] Ferreira, D. D. M., Christensen, F. E., Jakobsen, A. C., and et al., "Coating optimization for the ATHENA+ mission," Proceedings of SPIE $\mathbf{8 8 6 1}$ (2013).

[7] Della Monica Ferreira, D., Jakobsen, A., Massahi, S., Christensen, F., Shortt, B., Garnaes, J., Torras-Rosell, A., Krumrey, M., Cibik, L., and Marggraf, S., "X-ray mirror development and testing for the ATHENA mission," Proceedings of SPIE 9905 (2016).

[8] Massahi, S., Girou, D., Ferreira, D. D. M., and et al., "Investigation of Photolithography Process on SPOs for the ATHENA Mission," Proceedings of SPIE 9603 (2015).

[9] Massahi, S., Della Monica Ferreira, D., Christensen, F., Shortt, B., Girou, D., Collon, M., Landgraf, B., Barriere, N., Krumrey, M., Cibik, L., and Schreiber, S., "Development and production of a multilayer-coated x-ray reflecting stack for the athena mission," Proceedings of SPIE 9905 (2016).

[10] Della Monica Ferreira, D., Massahi, S., Christensen, F., Shortt, B., Bavdaz, M., Collon, M., Landgraf, B., Gellert, N., Korman, J., Dalampiras, P., Rasmussen, I., Kamenidis, I., Krumrey, M., and Schreiber, S., "Design, development, and performance of x-ray mirror coatings for the athena mission," Proceedings of SPIE 10399 (2017).

[11] Windt, D. L., "IMD - Software for modeling the optical properties of multilayer films," Computers in Physics 12, 360-370 (Jan. 1998).

[12] Oosterbroek, T. and ESA, "ATHENA telescope reference design and effective area estimates," tech. rep., European Space Agency (2014).

[13] Krumrey, M. and Ulm, G., "High accuracy detector calibration at the PTB four-crystal monochromator beamline," Nucl. Instr. and Meth. A 1175 - 1178, 467 - 468 (2001).

[14] Fuchs, D., Krumrey, M., Mueller, P., Scholze, F., and Ulm, G., "High precision soft x-ray reflectometer," Review of Scientific Instruments 66(2), 2248-2250 (1995).

[15] Massahi, S., Christensen, F., Della Monica Ferreira, D., Dalampiras, P., Svendsen, S., and Jafari, A., "The effect of nitrogen incorporation in boron carbide and iridium thin films," Proceedings of SPIE 10699 (2018).

[16] Mayer, J., Giannuzzi, L. A., Kamino, T., and Michael, J., "Tem sample preparation and fib-induced damage," MRS Bulletin 32(5), $400 ? 407$ (2007).

[17] Wirth, R., "Focused ion beam (fib) : A novel technology for advanced application of micro- and nanoanalysis in geosciences and applied mineralogy," European Journal of Mineralogy 16(6), 863 (2004).

[18] Giannuzzi, L. and Stevie, F., "A review of focused ion beam milling techniques for tem specimen preparation," Micron 30(3), 197 - 204 (1999).

[19] Li, J., "The focused-ion-beam microscope - more than a precision ion milling machine," JOM 58, 27-31 (Mar 2006).

[20] Li, C., Habler, G., Baldwin, L. C., and Abart, R., "An improved fib sample preparation technique for site-specific plan-view specimens: A new cutting geometry," Ultramicroscopy 184, 310 - 317 (2018). 
[21] Collon, M., Vacanti, G., Barriere, N., Landgraf, B., Guenther, R., Vervest, M., Van Der Hoeven, R., Dekker, D., Chatbi, A., Girou, D., Sforzini, J., Beijersbergen, M., Bavdaz, M., Wille, E., Fransen, S., Shortt, B., Haneveld, J., Koelewijn, A., Booysen, K., Wijnperle, M., Van Baren, C., Eigenraam, A., Mueller, P., Krumrey, M., Burwitz, V., Pareschi, G., Massahi, S., Christensen, F., Della Monica Ferreira, D., Valsecchi, G., Oliver, P., Checquer, I., Ball, K., Zuknik, K., O’Dell, S., and Pareschi, G., "Development of athena mirror modules," Proceedings of SPIE 1039910399 (2017).

[22] Tong, Q.-Y. and Goesele, U., "A model of low-temperature wafer bonding and its applications," J. Electrochem. Soc 143 (1996). 